\title{
Isolated Langerhans Cell Histiocytosis of the Thyroid Gland:
} A Rare Case

\author{
Jayalakshmi Venkateswaran ${ }^{1}$, Purnima Lad ${ }^{2}$, Satyakam Sawaimoon ${ }^{3}$, Chitralekha Soman $^{4}$, Simi Bhatia ${ }^{5}$, Premila Samuel ${ }^{6}$
}

\begin{abstract}
Langerhans cell (LC) histiocytosis (LCH) is a rare disease predominantly affecting children and young adults, with an annual incidence between 4 and 5.4 per million individuals. Involvement of the thyroid by LCH is very rare, even in a multifocal disease. It can easily be confused on clinical grounds with other more common entities such as undifferentiated carcinoma, lymphoma, lymphocytic thyroiditis, chronic granulomatous thyroiditis, and cystic degeneration of multinodular goiter. Histology remains the most sensitive diagnostic modality. Immunohistochemical studies are extremely helpful in confirming the histologic impression because LCs are positive for S-100 protein and CD1a, and both markers can be used to assess formalin-fixed, paraffin-embedded tissue sections. Electron microscopy is also helpful by allowing identification of the pathognomonic Birbeck granules but not essential for diagnosis. Single-organ involvement in LCH is associated with excellent survival close to $100 \%$. We report a rare case of isolated thyroid gland involvement by LCH.

Keywords: Langerhans cells, Langerhans cell histiocytosis, Thyroid.

International Journal of Head and Neck Surgery (2018): 10.5005/jp-journals-10001-1348
\end{abstract}

\section{INTRODUCTION}

Langerhans cell histiocytosis $(\mathrm{LCH})$ is a rare disease predominantly affecting children and young adults but it can be found in any age group. ${ }^{1}$ The annual incidence of LCH is between 4 and 5.4 per million individuals. ${ }^{2}$ LCH is considered a neoplasm of the mononuclear phagocytic immunoregulatory system of unknown etiology. The disease is characterized by clonal proliferation of a special kind of histiocyte of the antigen-presenting dendritic type called the LCs. The unifocal form of LCH (solitary eosinophilic granuloma) usually involves the bone. The multifocal unisystem form of $\mathrm{LCH}$ (Hand-Schuller-Christian disease) almost always occurs in the bone. The multifocal, multisystem form of LCH (Letterer-Siwe syndrome) involves many organs, including bone, skin, liver, spleen, and lymph node. ${ }^{1}$ The most common endocrinological manifestation of classical $\mathrm{LCH}$ is associated with the posterior pituitary, presenting as diabetes insipidus (DI). ${ }^{2}$ Involvement of the thyroid by LCH is very rare, even in the multifocal disease. The unifocal disease apparently confined to the thyroid is rare. ${ }^{3}$ The disease is confirmed by an electron microscopy or immunohistochemical reactivity of histiocytes to CD1a and/or S-100 protein. ${ }^{4}$ In this case report, we describe a case of isolated thyroid involvement by LCH.

\section{Case Description}

A 29-year-old woman presented with a thyroid mass. The only other complaint was scanty menses. Thyroid function tests revealed a thyroid stimulating hormone (TSH) value of $60 \mu \mathrm{lU} / \mathrm{mL}$ (range-0.35-5.5 $\mu \mathrm{lU} / \mathrm{mL}$ ). Ultrasonography (USG) showed a diffusely enlarged, hypoechoic thyroid gland without cervical lymphadenopathy. Correlating the patient's clinical symptoms with the investigations, a diagnosis of multinodular goiter with associated hypothyroidism was made. She was subsequently administered Thyroxine $50 \mu \mathrm{g}$ per day. The swelling did not regress and the patient underwent hemithyroidectomy.

\section{Gross Pathology}

The hemithyroidectomy specimen was received from the Department of Surgical Pathology. The left lobe and isthmus

\author{
${ }^{1-5}$ Department of Histopathology, SRL Diagnostics, Mumbai, \\ Maharashtra, India \\ ${ }^{6}$ Department of Histopathology, SRL Diagnostics, Bengaluru, \\ Karnataka, India
}

Corresponding Author: Jayalakshmi Venkateswaran, Department of Histopathology, SRL Diagnostics, Mumbai, Maharashtra, India, Phone: +91 9821448917, e-mail: dr.jayalakshmi1412@gmail.com

How to cite this article: Venkateswaran J, Lad P, et al. Isolated Langerhans Cell Histiocytosis of the Thyroid Gland: A Rare Case. Int J Head Neck Surg 2018;9(3):110-112.

Source of support: SRL Diagnostics

Conflict of interest: None

measured $4.5 \times 4.0 \times 2 \mathrm{~cm}$. The specimen was externally, gray brown, nodular. Cut section revealed a solid diffuse gray-white appearance with brownish areas. No focal nodule or lesion was noted.

\section{Microscopy}

Sections cut at $5 \mu$ were stained with the routine hematoxylin and eosin (H\&E) stain. Microscopy on 10x (low power) showed thyroid follicles with small lymphocytes forming reactive lymphoid follicles (Fig. 1). Higher magnification, 40x, revealed diffuse infiltration by large oval cells, having pale cytoplasm and vesicular nuclei showing prominent grooves and indentations-LCs (Figs 2 and 3). A few eosinophils were also noted (Fig. 3). To confirm the diagnosis of LCH, immunohistochemistry (IHC) was performed. Formalin-fixed, paraffin-embedded sections at $5 \mu$ were stained with antibodies against pan-cytokeratin-CK (DAKO), CD1a (DAKO), and S-100 (DAKO) using the avidin-biotin complex method and the microwave antigen retrieval technique. Positive and negative controls were carried out. On IHC, the large oval LCs were positive for CD1a (Fig. 4) and S100p (Fig. 5). The thyroid follicles were positive for CK (Fig. 6).

o The Author(s). 2018 Open Access This article is distributed under the terms of the Creative Commons Attribution 4.0 International License (https://creativecommons. org/licenses/by-nc/4.0/), which permits unrestricted use, distribution, and non-commercial reproduction in any medium, provided you give appropriate credit to the original author(s) and the source, provide a link to the Creative Commons license, and indicate if changes were made. The Creative Commons Public Domain Dedication waiver (http://creativecommons.org/publicdomain/zero/1.0/) applies to the data made available in this article, unless otherwise stated. 


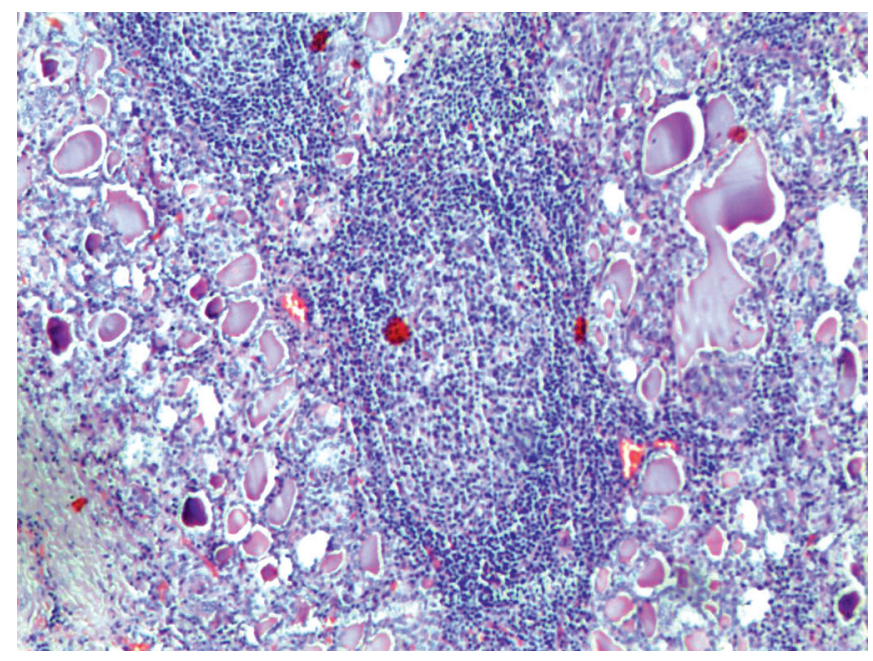

Fig. 1: Normal thyroid follicles admixed with lymphocytes forming follicles. H\&E, 10X

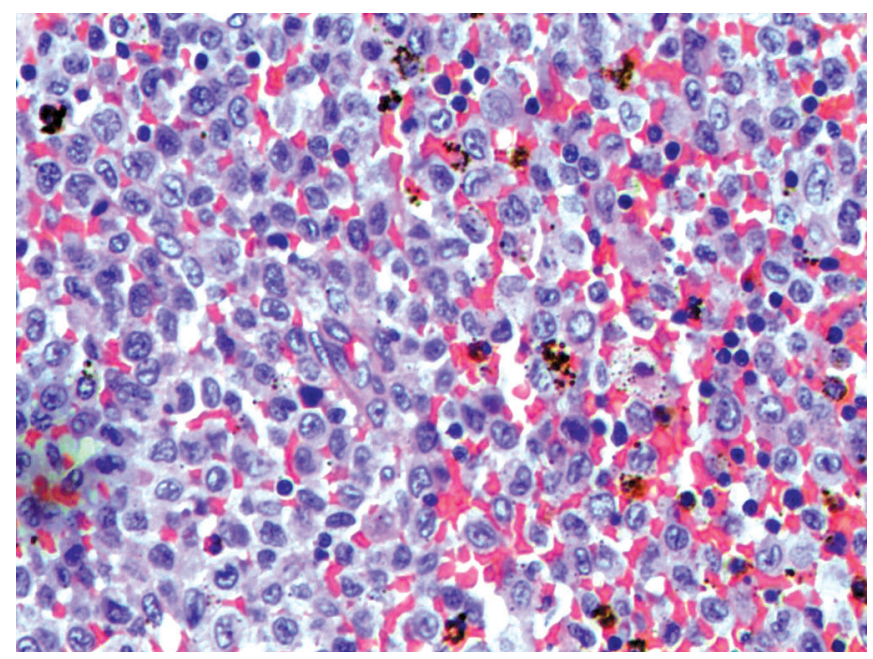

Fig. 3: Langerhans cells along with few eosinophils. $H \& E, 40 \times$

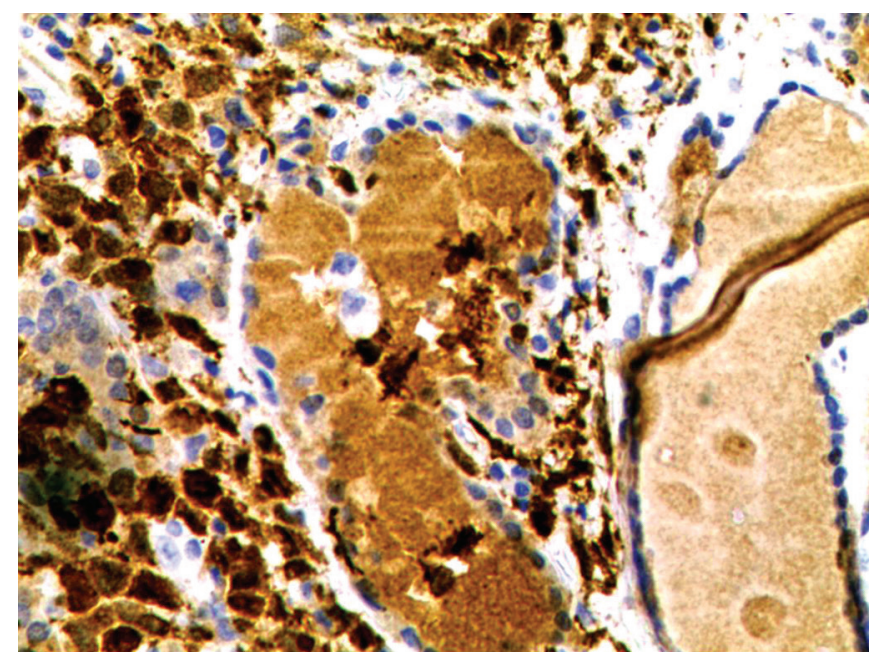

Fig. 5: S100p, 40X

\section{Discussion}

LCH, first described in 1893, is composed of large histiocytes with abundant cytoplasm intermixed with lymphocytes and

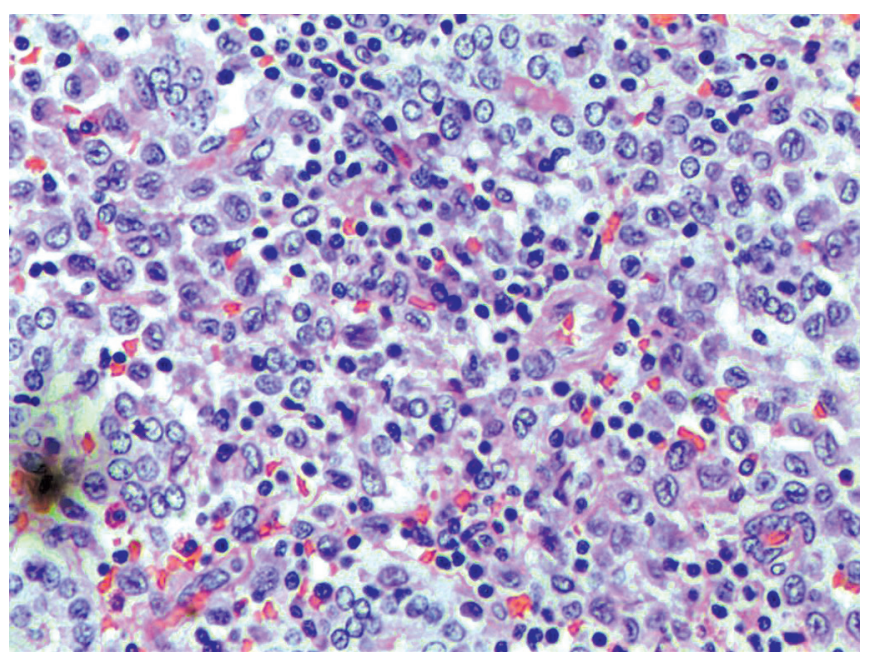

Fig. 2: Langerhans cells showing prominent grooves, with pale cytoplasm and vesicular nuclei. $\mathrm{H} \& \mathrm{E}, 40 \times$

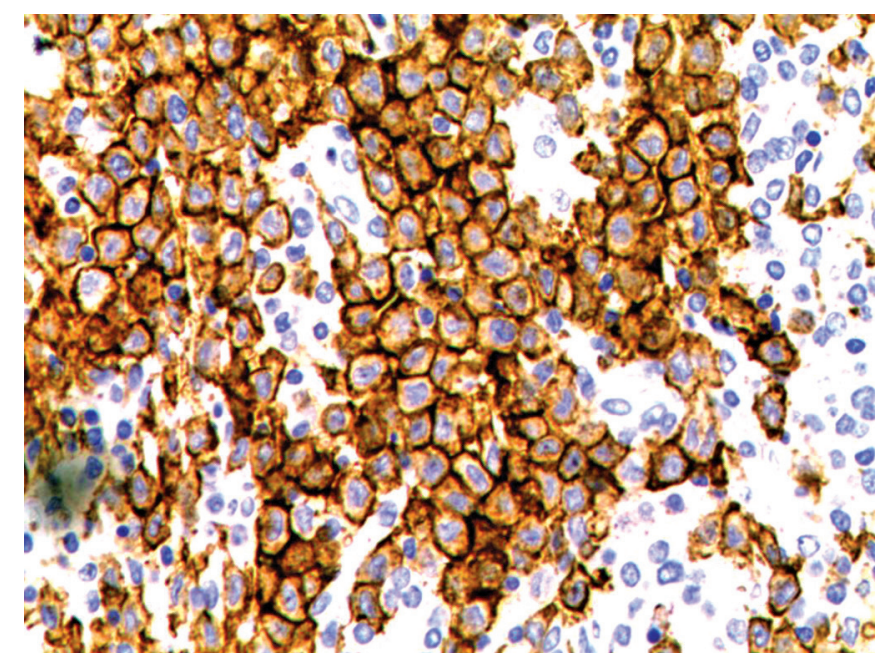

Fig. 4: CD1a, 40x

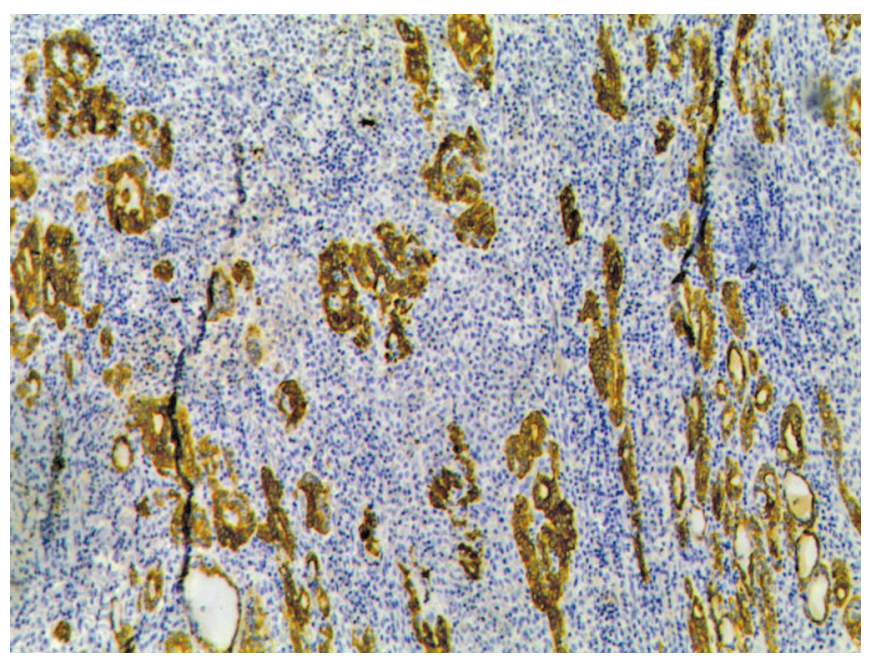

Fig. 6: $C K, 40 X$

eosinophils. ${ }^{2}$ LCH primarily involving the thyroid gland is extremely rare, and there are very few reported cases. Reported cases of thyroid gland infiltration by LCH are 34 ( 22 adults and 12 children). ${ }^{5}$ Due to its rarity, diagnosing LCH as a cause of goiter can be 
challenging. It can easily be confused on clinical grounds with other more common entities such as undifferentiated carcinoma, lymphoma, lymphocytic thyroiditis, chronic granulomatous thyroiditis, and cystic degeneration of multinodular goiter. ${ }^{4}$ Initial steps in the diagnosis of primary thyroid LCH involve investigations into the work-up of thyromegaly, namely, neck USG and fine-needle aspiration cytology (FNAC). Although FNAC may be useful in the diagnosis for thyroid $\mathrm{LCH}$, it has shown to be variable with some cases being misdiagnosed as "atypical follicular epithelial cells" and papillary or medullary carcinoma. Therefore, histology remains the most sensitive diagnostic modality, although there have been cases of histological misinterpretation of $\mathrm{LCH}$ interpreted as poorly differentiated carcinoma. LCs characterized by cytoplasmic rodshaped organelles (Birbeck granules) are a type of dendritic cell and are classed as antigen-presenting cells of the skin epidermis. ${ }^{2}$ The cytologic features of LCs are characteristic, in particular, the eccentric nuclei with folded nuclear contours and linear nuclear grooves. Immunohistochemical studies are extremely helpful in confirming the histologic impression because LCs are positive for S-100 protein and CD1a, and both markers can be used to assess formalin-fixed, paraffin-embedded tissue sections. Electron microscopy is also helpful by allowing identification of the pathognomonic Birbeck granules but not essential for diagnosis. ${ }^{1,6}$ At a molecular level, LCs express CD1a, langerin (CD207), and S-100 protein, but do not express markers which are possessed by mature dendritic cells such as CD83. ${ }^{2}$ Two inflammatory conditions to be considered in the differential diagnosis of LCH involving the thyroid gland are subacute granulomatous thyroiditis and chronic lymphocytic thyroiditis. The presence of eosinophils is extremely helpful for the correct diagnosis of $\mathrm{LCH}$, but these may be sparse, as seen in our case. The presence of giant cells and associated fibrosis in LCH may lead to an erroneous diagnosis of subacute granulomatous thyroiditis. The presence of numerous lymphocytes may lead to the misdiagnosis of chronic lymphocytic thyroiditis. ${ }^{6}$ Excluding LCH of the lung, which seems to be a separate syndrome, "multisystem" LCH disease has a worse prognosis than monofocal disease, with $10-30 \%$ mortality and a $50 \%$ risk of life-impairing morbidity. Thyroid involvement is more common in adults and has a relatively indolent course. It is important to distinguish isolated thyroid LCH from multisystemic cases because single-organ involvement is associated with excellent survival, close to $100 \% .^{7}$ For aggressive disease, multiple chemotherapeutic regimens have been attempted: glucocorticoids, vinblastine, etoposide, cyclophosphamide, methotrexate, and doxorubicin. ${ }^{5}$

\section{References}

1. Lee L-Y, Kang C-J, et al. Diagnosis of nodal langerhans cell histiocytosis by fine needle aspiration cytology. Chang Gung Med J 2005;28(10):735-738.

2. Patten DK, Wani Z, et al. Solitary langerhans histiocytosis of the thyroid gland: a case report and review of literature. Head and Neck Pathol 2012;6:279-289. DOI: 10.1007/s12105-011-0321-8.

3. Zhu H, Hu DX. Langerhans cell histiocytosis of the thyroid diagnosed by fine needle aspiration cytology. A case report. Acta Cytol 2004 Mar-Apr;48(2):278-280. DOI: 10.1159/000326332.

4. Behrens RJ, Levi AW, et al. Langerhans cell histiocytosis of the thyroid: a report of two cases and review of literature. Thyroid 2001;11:697-705. DOI: 10.1089/105072501750362781.

5. Braiteh F, Kurzrock R. Langerhans cell histiocytosis of the thyroid. J Clin Oncol 2006;24(3):522-527. DOI: 10.1200/JCO.2005.01.3763.

6. Elliott DD, Sellin R, et al. Langerhans cell histiocytosis presenting as a thyroid gland mass. Ann Diagn Pathol 2005;9(5):267-274. DOI: 10.1016/j.anndiagpath.2005.05.002.

7. Villagonga R, Ciudin A, et al. Isolated Langerhans Cell Histiocytosis of the Thyroid in an adult female: One year followup. Int J Endocrinol 2011;2011:898302. DOI: 10.1155/2011/898302. 